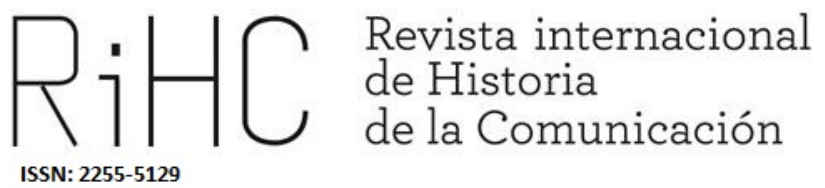

\title{
NEGOCIOS CULTURALES DEL ASTURIANO JUAN DE LA FUENTE PARRES EN MÉXICO
}

Cultural bussiness of the asturian Juan de la Fuente Parres in México

DOI: http://dx.doi.org/10.12795/RiHC.2019.i12.14

Recibido: $15 / 03 / 2019$

Aceptado: $14 / 05 / 2019$

Publicado: $15 / 06 / 2019$

Lilia Vieyra Sánchez

Universidad Nacional Autónoma de México

vieyra69@yahoo.com.mx

ORCID (D): 0000 0002-0046-8282 
Resumen: Este artículo reconstruye la biografía del editor asturiano Juan de la Fuente Parres, a través de las páginas de periódicos mexicanos y españoles. Establece la importancia de La Prensa que De la Fuente animó de 1883 a 1884, como la publicación que otorgó un mayor reconocimiento a dicho empresario peninsular en el ambiente cultural mexicano. Además, puntualiza la competencia editorial que existió entre De la Fuente Parres con el catalán Santiago Ballescá, sin dejar de lado el estudio de las redes de asturianos en México con escritores y políticos mexicanos.

Palabras clave: Juan de la Fuente Parres; editor asturiano; México; Periodismo siglos XIX yXX.

Abstract: This article reconstructs the biography of the Asturian editor Juan de la Fuente Parres, through the pages of Mexican and Spanish newspapers. Establishes the importance of La Prensa that De la Fuente animated from 1883 to 1884, as the publication that granted greater recognition to this peninsular entrepreneur in the Mexican cultural environment. He also points out the editorial competence that existed between De la Fuente Parres and the Catalan Santiago Ballescá, without neglecting the study of Asturian networks in Mexico with Mexican writers and politicians.

Keywords: Juan de la Fuente Parres; Asturian editor; Mexico; Journalism nineteenth and twentieth centuries.

\section{Introducción}

Dentro del ámbito editorial, Juan de la Fuente Parres es reconocido por publicar la obra Historia de Méjico (1877-1882) del español Niceto de Zamacois, que compitió con la edición de México a través de los siglos (1887-1889), animada por su coterráneo Santiago Ballescá (1856-1913) bajo la coordinación de Vicente Riva Palacio, junto con otros escritores liberales mexicanos como José María Vigil, Alfredo Chavero e inclusive en el equipo de autores se encontraba el peninsular Enrique de Olavarría y Ferrari (PiSuñer Llorens, 2010: 44-62). También se ha destacado la encomiable labor de edición que De la Fuente Parres realizó en las novelas de Manuel Payno El Fistol del diablo (1887) y Los bandidos de Río Frío (1891), elaboradas con calidad tipográfica en la imprenta que De la Fuente tenía en Barcelona, España (Sol, 2009: 93-95). ${ }^{1}$

A pesar de tan nobles antecedentes, poco se conoce de la biografía de Juan de la Fuente Parres: del lugar en que nació, sus actividades en la península, la fecha en que abandonó España, el año en que llegó a México, las ocupaciones que desarrolló en su país adoptivo y los giros comerciales a los que se dedicó. Ante esta falta de datos, Marléne Schmitt

\footnotetext{
${ }^{1}$ Agradezco a la Dra. Clara E. Lida la invitación para dar a conocer una versión previa de este texto en el Seminario Permanente México-España de El Colegio de México, que dirige con el Dr. Tomás Pérez Vejo. Los comentarios del Dr. Aimer Granados y las sugerencias de los miembros del Seminario fueron de gran utilidad para mejorar este artículo.
} 
(2001: 312) mencionó que De la Fuente era un editor catalán, cuando en realidad, como se explica en este artículo, era originario de Asturias, equivoco que surgió por el hecho de que su sello editorial estaba en Barcelona, como acabo de apuntar.

Aquí se construirá la biografía de Juan de la Fuente Parres, desde los periódicos mexicanos de los siglos XIX y XX, lo cual fue posible a través de la consulta de la Hemeroteca Nacional Digital de México, conjugada con información derivada en la Hemeroteca Digital de la Biblioteca Nacional de España y en la Biblioteca Virtual de Prensa Histórica del Ministerio de Educación, Cultura y Deporte del Gobierno de España. A los que se suman las obras que documentan su vida y actividad editorial: un alegato judicial (Mateos Cardeña, 1903), una querella testamentaria promovida por su hija Concepción de Fuente (Chavarín, Briones, MacGregor, 1924) y los estudios de la historiadora Antonia Pi-Suñer en torno a la Historia de Méjico de Zamacois, que editó Juan de la Fuente, comparada con México a través de los siglos de Ballescá (Pi-Suñer Llorens, 2017: 355-365).

Escribir la biografía de una persona a través de la información que proporcionan las páginas de periódicos puede correr el riesgo de brindar un perfil parcial del individuo, -notas publicitarias que él contrataba en los diarios en donde se empeñó en forjar una imagen acorde a sus intereses, o entrevistas que destacaban su versión personal-, lo que promueve que la investigación hemerográfica debe acompañarse de la consulta de documentos y libros. ${ }^{2}$ Sin embargo, a través de la revisión de La Prensa fue posible identificar a este personaje del que poco se conoce y ha estudiado, aspecto que resulta novedoso, ya que es poco común este tipo de abordaje, con los trances que entraña. ${ }^{3}$

Cabe apuntar que las páginas de periódicos y revistas constituyen documentos de gran utilidad que permiten saber los nombres de notarios con los que De la Fuente realizó sus gestiones, apostillas relacionadas con finiquito de sociedades financieras, edictos y datos acerca de los procedimientos que ejercía para adueñarse propiedades que le habían hipotecado. Queda como tarea pendiente la revisión de archivos parroquiales en Asturias, las actas del Casino Español y los registros notariales de la Ciudad de México que, indudablemente, fijarán un perfil más completo de este empresario de la cultura.

\footnotetext{
${ }^{2}$ El Dr. Tomás Pérez Vejo alertó sobre los problemas que implican ceñir la vida de un personaje únicamente en la revisión de periódicos, así como la importancia de complementar y contrastar estos datos con lo que pueden obtenerse en diversos archivos españoles y mexicanos.

${ }^{3}$ El estudio y análisis de La Prensa forma parte del Proyecto de investigación Periódicos de corta vida durante el cuatrienio gonzalista, que desarrollo en el Instituto de Investigaciones Bibliográficas de la Universidad Nacional Autónoma de México, cuyos objetivos son sistematizar las publicaciones que aparecieron durante el gobierno de Manuel González (1880-1884), resguardadas en el Fondo Reservado de la Hemeroteca Nacional de México y destacar la importancia de particularizar la administración de ese presidente como un periodo que merece estudiarse más allá de englobarlo dentro del porfiriato, como la historiografía tradicional lo ha situado.
} 
El artículo pretende responder a las siguientes interrogantes: ¿Cuál es la aportación de la migración asturiana a México en el ámbito editorial? ¿Cómo se gesta la trayectoria de un comerciante que inicia como comisionista, se erige como editor y alcanza el rango de librero? ¿De qué manera capitalizó Juan de la Fuente Parres las relaciones que sostuvo con los asturianos que lo integraron a un ambiente elitista, tanto en el Casino Español como en el círculo de políticos mexicanos? ¿Qué significó para Juan de la Fuente editar el periódico La Prensa? ¿Qué papel ocupó De la Fuente en el ambiente cultural mexicano? ¿Qué competencia tenía este editor asturiano y cómo la enfrentó?

Por otra parte, aquí se sostiene la hipótesis de que la incursión de Juan De la Fuente Parres en la edición del periódico La Prensa (1883 a 1884) será crucial para consolidar su presencia entre letrados y políticos mexicanos. La investigación tratará de demostrar que, a partir de que De la Fuente elabora ese periódico, se relacionará con escritores liberales y conservadores que contribuirán a perfilarlo como un editor-librero especializado en la producción y venta de textos religiosos. Por medio de La Prensa, De la Fuente Parres será reconocido en el terreno periodístico donde polemizó con Santiago Ballescá por realizar las mejores ediciones de libros. Además, el apoyo que De la Fuente suministró a Porfirio Díaz en ese periódico será fundamental para acercarlo al presidente mexicano, obtener su respaldo en el negocio editorial y luego como poderoso hacendado.

\section{Construcción biográfica de Juan de la Fuente Parres a través de la hemerografía}

Juan de la Fuente de Parres nació en 1847 en Niembro, Consejo de Llanes, Asturias, España (Chavarín, Briones, MacGregor, 1924: 22). Hijo legítimo de José de la Fuente Balmori y Ramona Parres Piñera, Juan salió de España en 1863, cuando tenía 16 años de edad, dato que La Prensa, periódico publicado en la Ciudad de México, proporciona en 1884, e informa que De la Fuente tenía “en el país más de veintiún años, en cuyo tiempo y a fuerza de su honradísimo trabajo, ha logrado una posición independiente sin recurrir a medios que a otros en pocos meses han logrado enriquecer" (La Prensa, 6 de diciembre de 1884: 1). Esta información puede corroborarse en la tarjeta de presentación que José Parres, tío de Juan de la Fuente, le proporcionó en Llanes, con fecha octubre de $1863 .^{4}$

\footnotetext{
${ }^{4}$ Agradezco a Guadalupe de la Fuente, bisnieta de Juan de la Fuente Parres, darme a conocer este documento. Cabe señalar que conocí a la descendiente de este editor asturiano por la difusión que el
} 
Es posible identificar que De la Fuente llegó a México recomendado con los asturianos Manuel Mendoza, José de Teresa, Faustino Sobrino y Santos Peláez. A través de estos personajes puede conocerse un entramado de redes de parentesco, paisanaje $y$ negocios que caracterizaron la migración peninsular a México. Es así que sabemos que Santos Peláez era tío de Ramón Balmori, al que quizá le unía una relación consanguínea con el padre de Juan de la Fuente, quien llevaba el apellido Balmori. Esos cuatro peninsulares tenían un lugar destacado en el ambiente mercantil de Puebla, Veracruz y la capital de la República Mexicana. Amén de que gozaban de cargos de dirección en el Casino Español y la Beneficencia Española. Precisamente el año de 1863 en que De la Fuente Parres llegó a la República Mexicana se estableció el Casino Español, asociación que congregaba a los comerciantes peninsulares en México, que previamente se habían organizado en la Sociedad de Beneficencia Española, fundada en 1842.

La relación de Juan de la Fuente con estos migrantes asturianos privilegiados en México, permiten dudar o matizar el origen humilde que trató de fraguarse a través de una entrevista que le realizó el periodista español Mariano José Madueño, lo que sugiere la creación de una autobiografía acorde a sus intereses y difundida a través del periódico, medio de comunicación controlado y dirigido por los comerciantes de la cultura. Estas palabras las reprodujo el periódico mexicano El Tiempo:

Soy asturiano, del Concejo de Llanes, pueblo de Niembro, en donde apenas aprendí a juntar las letras. No conocí nunca la gramática ni la ortografía. Antes de venir aquí, donde llevo cerca de 40 años, fue mi escuela literaria la "Tejera", industria bien pobre de los de mi Concejo, y aquí, a fuerza de costumbre, escápaseme no pocas veces poner honra sin la " $\mathrm{h}$ " $\mathrm{y}$ algunas veces con dos "erres". Mi Ateneo aquí fue, desde que llegué, la tienda de abarrotes (ultramarinos, como ahí se llaman) y a los diez años, me establecí en el giro de publicaciones. Con que ya ve usted que distante estoy del concepto en que usted me tenía, al que en realidad debe ser, y sentiría que esto influyera en su ánimo para considerarme menos (El Tiempo, 31 de marzo de 1905: 2).

Es probable que se tratara de un hombre con una posición económica que le permitía ejercer recursos para comprar el boleto de barco que lo llevara del puerto español al mexicano. ${ }^{5}$ Quizá Juan era el pariente pobre de acaudalados comerciantes asentados en México, los cuales también habían abandonado España para "hacer la América" con éxito y eso promovía el interés de sus familiares por seguir su ejemplo. La historiografía

Seminario Permanente México-España de El Colegio de México hace de sus actividades. En la tarjeta se leen además los nombres de Toribio y José Noriega, también oriundos de Asturias.

${ }^{5}$ Cabe citar el caso del asturiano Iñigo Noriega Laso, cuya familia había gozado de una posición financiera sólida que perdió a causa de los problemas políticos y económicos que afectaron a España, según establece la investigación de su descendiente (Noriega Gayol, 2002: 31-40). Agradezco a la Dra. Laura Edith Bonilla de León que me haya proporcionado este dato. 
ha señalado que los peninsulares llegaban a México en la pobreza extrema y a fuerza de trabajo constante y esfuerzo lograban forjarse un porvenir venturoso. Aunque la prensa decimonónica fomentó esa versión, cabe preguntarse hasta qué punto los propios españoles fueron responsables de que se les identificara de esa manera, con testimonios que establecían que su posición económica era producto de su brío, sin despojar a los mexicanos de sus bienes para obtener fortuna.

Entre los personajes a quien venía recomendado De la Fuente Parres figura el asturiano José de Teresa, activo en el comercio poblano y que dirigió el ferrocarril de Tlalpan en colaboración con José María Iglesias, lo que prefigura las relaciones que Juan de la Fuente estrechó con políticos mexicanos, a partir de los lazos que sus paisanos habían tejido. De Teresa sostuvo una buena relación con Porfirio Díaz, quien asistió a su funeral a fines de 1870 (Portilla de la, 1870: 3).

De la Fuente Parres señala que desarrolló una labor intensa para conquistar una buena posición económica, que le llevó a trabajar en una tienda de abarrotes durante una década y luego se estableció en el giro de publicaciones. Hasta ahora desconozco quién le introdujo en esa actividad comercial, es probable que alguno de sus compatriotas que formaba parte del Casino Español y que también destacó en el comercio poblano y veracruzano, lo que un análisis acucioso responderá. ${ }^{6}$ Lo cierto es que desde 1872 fue gerente de la empresa J. F. Parres y Compañía de la que se convertirá en propietario el 16 de agosto de 1889 (El Tiempo, 8 de abril de 1890: 3).

Juan, al igual que otros españoles que forjaron alianza con México a través del matrimonio con mujeres oriundas de este país, se casó en 1876, a la edad de 21 años, con Concepción Elena Nieto, con la que procreó varios hijos (se desconoce el número exacto, pues la disputa por su testamento enfrentó a los vástagos de sus dos esposas que dejaron confuso ese dato). Enviudó de la señora Nieto en 1898, pero con Isabel Abat sostuvo una relación extramarital en San Felipe del Progreso, Ixtlahuaca, donde se ubicaba su hacienda, por lo que celebró segundas nupcias en 1912, cuando tenía 65 años de edad.

Después de 14 años de estancia en la República Mexicana, en 1877 editó la Historia de Méjico de Zamacois. Aunque la obra fue importante, De la Fuente carecía de reconocimiento en el ambiente editorial mexicano, inclusive dentro del Casino Español era un miembro sin renombre pues cuando su hija Concepción de la Fuente contrajo nupcias con Adolfo Llanos y Alcaraz, escritor y periodista cartagenero, el año de 1874, poco se dijo del prestigio editorial de Juan de la Fuente, que sólo firmaba con su primer apellido (Vieyra Sánchez, 2014: 108).

\footnotetext{
${ }^{6}$ En otra etapa de la investigación valdría la pena concentrarse en los nombres de Francisco Ituarte, Maclovio Ramos y Alejandro Valdés Flaquer, con los que De la Fuente constituyó su Compañía Editorial.
} 
El círculo comercial y amistoso al que pertenecía De la Fuente Parres le permitió relacionarse con el presidente Porfirio Díaz, lo que hizo posible que antes de que terminara su primera administración en 1880 , Juan de la Fuente obtuviera un contrato para elaborar libros en blanco que requerían las aduanas marítimas y fronterizas, el 30 de noviembre de ese año. Esta situación provocó que El Monitor Republicano protestara por la irregularidad de la operación que debió hacerse en remate público. El Diario Oficial contestó que ese acto convenía a la Secretaría de Hacienda porque De la Fuente haría el trabajo por una cantidad que permitiría el ahorro al erario nacional (El Monitor Republicano, 9 de marzo de 1881: 3).

Bajo el gobierno de Manuel González, De la Fuente cosechó los primeros frutos de sus relaciones con los socios del Casino Español y políticos mexicanos. En 1882, cinco años después del inicio del proyecto editorial, concluyó la publicación de la Historia de Méjico de Zamacois. En esos momentos la situación era diferente, a De la Fuente se le conocía en el ámbito cultural y el capital financiero que poseía le permitía pagar anuncios periodísticos que publicitaban obras como la Biblioteca Universal e llustración Artística (El Diario del Hogar, 13 de junio de 1882: 2).

Es así como De la Fuente utilizó una novedosa oferta editorial y estrategia publicitaria al incluir la información en la segunda plana del diario, lo que le daba más presencia ante el público lector, pues usualmente este tipo de información iba en la última página. Además, el anuncio pagado por De la Fuente tenía una larga extensión y otras características que lo prefiguraban como artículo que destacaba las cualidades personales del editor y de la obra, describía que De la Fuente era amable, activo, inteligente, amistoso y apreciado por los mexicanos, lo que más que una opinión del redactor del diario, representaba la manera en que el anunciante quería mostrarse al consumidor para obtener su aceptación. ${ }^{7}$

Ante una nueva etapa de transición presidencial, De la Fuente editó el bisemanario La Prensa (1883-1884) que promovió la candidatura de Porfirio Díaz, a quien respaldó en las sucesivas candidaturas como miembro del Círculo Nacional Porfirista que trabajaba con otros destacados mexicanos y españoles. La tercera reelección de Díaz hizo patente la cercanía del editor asturiano con el presidente mexicano, ya que años después, al finalizar la década de 1880, la Casa Editorial de De la Fuente Parres gozaba de amplio prestigio, inclusive la Guía descriptiva de 1889 se ocupó de hacer una visita e ilustró las oficinas de su imprenta, lo que se incluyó en varias páginas de esa publicación.

Durante la década de 1890, De la Fuente experimentó un crecimiento empresarial significativo, pues disolvió la sociedad editorial Ituarte Parres y Compañía que giraba en

\footnotetext{
${ }^{7}$ La venta y distribución de la colección de esta Biblioteca Universal duró varios años, en 1890 todavía ocupaba la publicidad de las páginas de periódicos mexicanos como La Patria de México dirigido por Ireneo Paz.
} 
la Calle de Chiquis en la Ciudad de México; Pastora 2 en Veracruz y Consejo Ciento 301 y 303 en Barcelona y además se convirtió en propietario de la Librería Religiosa del Sagrado Corazón de Jesús y Centro de Publicaciones Españolas, ubicadas cerca del Sagrario de Guadalajara, México (Fuente Parres, 1893: 3).

Durante la segunda mitad de la década de 1880 y los primeros años de 1890, Juan de la Fuente Parres estableció una amplia y completa librería en la que promovió la importación, distribución y venta de diccionarios, obras de historia, geografía, literatura, religión, ciencia, medicina, arquitectura, agricultura, zoología y arte de escritores españoles, mexicanos y europeos que contribuyeron al avance cultural de México (De la Fuente, 1894).

Versado en el giro de venta de obras religiosas, De la Fuente aprovechó las ediciones que en 1883 y 1884 había hecho a la obra de Fernando Álvarez Prieto, La virgen del Tepeyac, que publicitó en 1895 como un texto aprobado por la autoridad eclesiástica. La venta de ese libro era la posibilidad de realizar un gran negocio, ya que en ese año tenía lugar la coronación guadalupana, lo que permitía aprovechar el fervor católico para capitalizarlo en el consumo de libros relacionados con el tema. Es así que De la Fuente distribuyó en su librería la obra de Juan Luis Tercero, La causa guadalupana en los últimos veinte años (1875-1895). De sus talleres también salieron libros del sacerdote francés, Regis Planchet, quien residió temporalmente en México y que las autoridades eclesiásticas respaldaron (León-Portilla, 1986: 2298). La buena relación que De la Fuente tenía con el clero mexicano hizo posible que le solicitaran la edición de la Gaceta Eclesiástica Mexicana. Órgano oficial del Arzobispado de México.

En suma, Juan de la Fuente Parres conocía el negocio editorial, la oferta y la demanda, sabía acercarse a sus clientes mexicanos a los que ofertaba obras tanto nacionales como españolas, primordialmente las de tema religioso. Además de lectores-compradores mexicanos, el editor asturiano se relacionó con sus compatriotas residentes en México para ofertarles libros de escritores españoles como José Zorrilla, Benito Pérez Galdós y Juan Valera. Con este propósito, De la Fuente contrató espacios publicitarios en periódicos peninsulares editados en la capital de la República Mexicana, tales como El Correo Español, órgano de información de los empresarios asociados en el Casino Español.

Amén del comercio de libros, De la Fuente también ofrecía retratos del rey de España, Alfonso XIII "vestido con uniforme de cadete de infantería" (El Correo Español, 5 de agosto de 1896: 3) y vendía almanaques ilustrados con personajes peninsulares: la reina María Cristina, Emilio Castelar, Práxedes Sagasta, Antonio Cánovas, así como alegorías de España y la Guerra de Cuba. A los mexicanos también les atendió su fervor partidista con retratos del presidente Porfirio Díaz con uniforme montando en un caballo. Además de mapas de la República Mexicana que publicitaba como de gran utilidad para las escuelas, lo que vislumbra un fructífero mercado educativo de consumo. 
Juan de la Fuente Parres se dedicó a otras actividades. Visitó San Felipe del Progreso (1892), región favorable para la producción de zacatón, lo que le llevó a considerar que se trataba de un negocio redituable, por lo que compró la Hacienda de Tierra Quemada a la que le cambió el nombre por La Providencia que exportó zacatón a Alemania e Italia (Gutiérrez, Gudiño, 2001: 164). Además, en 1896 comerciaba con la venta de madera extranjera, especial para empaque. ${ }^{8}$

Del mismo modo en que se distinguió como un importante editor, la última década del siglo XIX le vio erigirse como un productivo hacendado gustoso de participar en certámenes de ganado vacuno, bovino y equino que obtenían reconocimiento por su calidad. A esos concursos acudía como parte de las comitivas que acompañaban al presidente Díaz. En 1897 inauguró una importante maquinaria agrícola que dio lustre y producción a su hacienda, por lo que se le reconoció como el introductor del progreso, la riqueza y la prosperidad. Además de la labor agrícola, De la Fuente también se dedicó a la minería y explotó los yacimientos de las minas "Anexas de la Descubridora" ubicadas en San Felipe del Progreso.

De la Fuente obtuvo permiso en septiembre de 1896 para tender una línea telefónica entre su editorial ubicada en la calle de Santa Inés, Ciudad de México, a su Hacienda La Providencia, en San Felipe del Progreso, lo que se consideró una contribución "al progreso y al adelanto" de México (El Correo Español, 21 de noviembre de 1896: 1). De la Fuente también promovió enlazar la línea telefónica de su editorial a la colonia Santa María la Ribera, donde se hallaba la Comisión de Policía de la capital de la República Mexicana, acto poco altruista, pero que le permitía proteger sus bienes.

El éxito paralelo de sus negocios editorial, agrícola y ganadero ocasionó que De la Fuente dejara en manos de Ramón de San Nicolás de Araluce (1865-1941) su editorial, talleres de imprenta y encuadernación, lo que representó para este aprendiz de editor santanderino una gran formación en la producción y venta de libros que le habría de significar un negocio rentable. Emilio Pascual señala que De la Fuente Parres desarrolló una relación más estrecha con Araluce que con sus propios hijos, por este motivo "en vida quiso legarle la editorial. Pero Ramón se negó a aceptar ningún regalo e hizo lo que se hace en tales casos: lanzar una especie de OPA - 'hostil o amistosa, da lo mismo' - y comprar la editorial" (Pascual, 2010). ${ }^{9}$

\footnotetext{
${ }^{8}$ Sumada a esa actividad, en su Hacienda La Gavia también se ocupó de la producción agrícola y ganadera, explotaba bosques y pastos, rentaba fracciones de terrenos, cobraba por el uso de agua y prestaba dinero con altos intereses.

${ }^{9}$ Ramón de San Nicolás de Araluce vivió algunos años en México hasta que se enamoró de una catalana y marchó a Barcelona donde estableció su negocio que atendía personalmente con empeño y afán de publicar las mejores obras de interés y utilidad para los españoles. Emilio Pascual señala que Araluce fue nombrado presidente de la Cámara de Comercio Mejicana en España, lo que sirvió para que durante la Guerra Civil Española se respetara su integridad, la de su familia y negocio. Pascual identifica a Araluce
} 


\section{Juan de la Fuente Parres, editor de La Prensa (1883-1884)}

La década de 1880 representa una etapa importante en la actividad empresarial de este negociante de libros. Entre los proyectos editoriales que emprendió, el periódico $L a$ Prensa constituye un referente obligado para identificar su prestigio en el ambiente cultural basado en que el ingreso a la arena periodística le dará reconocimiento entre los escritores mexicanos de ideología liberal y conservadora. A finales de octubre de 1883 , como ya se mencionó, este comerciante asturiano de las letras, decidió apoyar la candidatura de Díaz para ocupar la presidencia nacional. Con este afán, publicó La Prensa, bisemanario que deja ver el posicionamiento que De la Fuente había adquirido, lo que hizo posible que José María Vigil, escritor jalisciense y político liberal destacado, accediera a dirigir y redactar esa publicación en la que también colaboraron el diplomático Juan de Dios Peza, Manuel Dublán, Julio Zárate, Ramón Manterola y Agustín Arroyo de Anda, entre otros.

En el arranque de ese proyecto periodístico, De la Fuente consideró que La Prensa podía ser una empresa pequeña, inclusive aceptó que Vigil le dedicara poco tiempo y que la mayor parte de las páginas del periódico fueran ocupadas con el Informe que en el último día de su periodo constitucional da a sus compatriotas el presidente de los Estados Unidos Mexicanos Porfirio Díaz acerca de los actos de su administración, documento que recordaba los aciertos de ese mandatario que merecía ser reconocido para volver a guiar a la nación.

La experiencia periodística y política que Vigil había adquirido le hizo proceder con cautela y aunque se decantaba por lucir la figura de Díaz como la persona más idónea para dirigir a México, reconocía los aciertos que durante la administración de Manuel González había logrado el país en crecimiento económico y desarrollo de infraestructura ferrocarrilera que hacía posible la comunicación con Estados Unidos de América. Inclusive, en un balance del año 1883, concluía que el país tenía un periodo de paz que permitió el auge de la ciencia, la industria y el desarrollo de la riqueza, lo que entreveía un porvenir venturoso para México. Esta línea editorial mostraba que Juan de la Fuente abanderaba la causa porfirista sin desacreditar a González, de quien había merecido el respaldo editorial que había obtenido de Díaz. Además de la propaganda política, como buen negociante, De la Fuente aprovechó la cuarta plana de La Prensa para publicitar su Catálogo general de las obras que completas y por suscripción se hallan en venta en la casa editorial de J. F. Parres y Compañía, Chiquis número 11. Este material es de gran valor para conocer los libros ofertados, la producción editorial, los autores, las

como un editor que contribuyó a la instrucción y deleite de una generación de peninsulares que disfrutaron de leer Las mil y una noches, La llíada y La Odisea. 
preferencias de los lectores y la publicidad que se empleó para generar interés en adquirirlos. $^{10}$

La carrera electoral incrementó la publicación de periódicos, Díaz empleó los recursos económicos para su campaña que financió diversos diarios. De esta manera, De la Fuente logró respaldo para incrementar la calidad de La Prensa. Solicitó a Vigil que le dedicara más tiempo a la redacción, pues el bisemanario se convertiría en diario. Don José María declinó este compromiso que ameritaba mayor atención, pues tenía que ocuparse de las labores que implicaban dirigir la Biblioteca Nacional de México, que abrió sus puertas el 2 de abril de 1884. Ante la renuncia de Vigil, De la Fuente Parres contrató a Alfredo Chavero, quien conformó a su cuerpo de redactores con los escritores Agustín F. Cuenca, Eduardo Zárate y Alberto G. Bianchi que hicieron más dinámico al periódico.

De esta manera, De la Fuente fungió como propietario de una empresa periodística que contrató a escritores mexicanos que se sentían agradecidos con el editor asturiano por abrir una fuente de trabajo que les permitía obtener un salario con el que podían ganarse la vida. ${ }^{11}$ Mención especial es el caso de Agustín F. Cuenca, que mereció el respaldo de Juan de la Fuente Parres, quien también apoyó a su viuda la escritora Laura Méndez de Cuenca con los gastos de la enfermedad que llevaron al sepulcro a su marido (Agüeros, 1884: 4). ${ }^{12}$

\footnotetext{
${ }^{10}$ Una línea de investigación que puede seguirse es la publicación de libros de tema histórico mexicano escritos por peninsulares como son los casos de Historia de Méjico de Niceto de Zamacois, Episodios históricos mexicanos de Enrique de Olavarría y Cuauhtémoc o el mártir de Izancanac. Novela histórica de Emilia Serrano La Baronesa de Wilson. Sin dejar de lado que De la Fuente también editó textos de historia de España como Los guerrilleros de 1808, Historia del Partido Republicano Español e Historia de la prostitución en España y América, los tres de la pluma de Enrique Rodríguez Solís; de Miguel Morayta Historia general de España, mientras que de Modesto Lafuente otra Historia general de España. Destaca además la nutrida obra de sus compatriotas Enrique Pérez Escrich: El amor de los amores, El pan de los pobres, La esposa mártir, La calumnia, El mártir del Gólgota, La promesa sagrada, El ángel de la guarda, El infierno de los celos, La duquesa de Martel, Las obras de misericordia, La caridad cristiana, El libro de Job, Los ángeles de la tierra, Los que ríen y los que Iloran, Escenas de la vida, La hermosura del alma, La envidia, La buenaventura, El camino del bien, El último beso y Los hijos de la fe. Y de Julián Castellanos y Velasco: La luz del cristianismo, La monja de las Ilagas, El mendigo de Madrid, El santuario del hogar, La ciega del Manzanares, La sultana loca, Locura de amor, El destripador de mujeres, El hijo de la noche, La virgen María, La hija del crimen, El calvario de una madre, La sed de oro, Luchar contra el destino o el delincuente honrado, Ensueños de oro, El juramento de los héroes, Advocaciones de la virgen, El favorito de la reina, La bruja, La hija del verdugo, La fiebre de la ambición y Los maldicientes. Sin dejar de lado diversos títulos de Manuel Fernández y González, entre otros autores y temas. Amén de que distribuyó las revistas España y América, El Salón de la moda, La llustración artística, Crónica del sport y El Centenario.

${ }^{11}$ Entre otros casos de escritores que colaboraron al lado de un editor español y le agradecieron el empleo, se cuenta Guillermo Prieto, quien fue asalariado del cartegenero Adolfo Llanos, que le abrió las puertas de La Colonia Española (Vieyra Sánchez, 2015: 92-94).

${ }^{12}$ Cabe señalar que los redactores de La Prensa eran dramaturgos que además de escribir el periódico colaboraron con De la Fuente en una función dramática realizada a beneficio de las víctimas de una inundación registrada en Pachuca (El Siglo Diez y Nueve, 27 de octubre de 1884: 2). De la Fuente también
} 
Las mejoras de La Prensa también se reflejaron en que la Tipografía "El Gran Libro", en que se imprimía, se pudieran trasladar de la calle de Tiburcio 13 y 18 a 1 a. de Independencia número 2, lugar mejor ubicado y que gozaba de instalaciones espaciosas. Este local se hallaba enfrente de la Casa de Diligencias, lo que constituía un punto estratégico, tanto para La Prensa, pues los pasajeros podían colocar sus avisos o suscribirse al diario, como para la Tipografía de "El Gran Libro", que dejaba ver la riqueza de su producción editorial.

El 15 de septiembre de 1884, fecha de regocijo cívico para los mexicanos, representó también el triunfo de Díaz para dirigir la presidencia del país. La Prensa reflejó este acontecimiento con la inclusión de un cabezal adornado con imágenes de un ferrocarril, postes de teléfono o telégrafo, un globo aerostático y una prensa, símbolos del avance en las comunicaciones y su efecto en el desarrollo de México. Al centro del cabezal se colocó un sol cuyos rayos alumbraban al águila que devoraba a una serpiente, parada sobre un nopal, la cual era enmarcada por unas hojas de laurel. Este aspecto evidencia el grado de conocimiento que De la Fuente tenía del valor de las insignias mexicanas.

Luego de que Díaz triunfó en las elecciones presidenciales, De la Fuente Parres vendió La Prensa a Agustín Arroyo de Anda y continuó, tanto en el negocio editorial como en la política mexicana, cobijado por el Club Donato Guerra que lo integró en una lista de candidatos a regidores, donde también destacan los nombres de otros españoles como José V. del Collado y Félix Cuevas, sin dejar de mencionar a impresores mexicanos como Francisco Díaz de León e Ireneo Paz (La Patria de México, 9 diciembre 1884: 2).

\section{Competencia editorial de Juan de la Fuente Parres y Santiago Ballescá}

La transición del gobierno de Manuel González a la primera reelección de Porfirio Díaz es el escenario en el que De la Fuente Parres obtiene un mayor reconocimiento en el ambiente cultural mexicano, esto a partir de la publicación de La Prensa, como enuncié antes. Las páginas de ese periódico registran una controversia entre el editor asturiano y su compatriota catalán Santiago Ballescá que muestran la competencia que implicaba el mercado editorial mexicano en esa época.

De la Fuente Parres planeaba publicar La Biblia sagrada traducida por Félix Torres Amat, obispo de Astorga y corregida por el académico Cayetano Rosell, a lo que sumaba el gran

mostró su espíritu caritativo con los habitantes de su natal Niembro, donde mandó a construir "un lavadero y fuente pública" (Ayuntamiento de Llanes, 20 de marzo de 1914: 6). 
valor de las ilustraciones de Gustavo Doré. ${ }^{13}$ En esa época, la publicación de una obra implicaba ganar la aceptación de los suscriptores quienes elegían el texto que comprarían a plazos. Al mismo tiempo que De la Fuente preveía la publicidad de $L a$ Biblia, Santiago Ballescá se ocupaba de ultimar los detalles para iniciar la venta de México a través de los siglos, cuya campaña propagaba que se trataba de un texto único, novedoso y con profusión de imágenes de calidad.

La competencia entre los dos editores españoles registra aristas interesantes que permiten apreciar la mercadotecnia que en la década de 1880 empleaban los comerciantes del libro, así como el apoyo de periodistas mexicanos y españoles a uno u otro de sus colegas. De la Fuente argumentó que tenía tradición y antigüedad en el mercado mexicano, mientras que Ballescá se había integrado más tarde. En efecto, De la Fuente tenía razón, Ballescá estableció su negocio años después que él, pues Santiago llegó a México procedente de su natal Barcelona en 1870 acompañado de su padre, ambos fundaron la compañía J. Ballescá que seis años después quedó a cargo de Santiago, lo que le permitió formar una familia con la mexicana Elena Palacios (Leal Miranda, 2008: 159-170).

De la Fuente Parres concentró la competencia de ambas obras en las imágenes que les acompañaban, pero luego argumentó que antes que Ballescá, él había publicado una Historia de Méjico redactada por Niceto de Zamacois, con lo que reclamaba el mérito de originalidad como editor y para Niceto como autor, lo que Pi-Suñer ha referido con detalle al documentar la rivalidad que existió entre Ballescá y De la Fuente Parres (PiSuñer Llorens, 2017).

La aportación que ofrece La Prensa a esta controversia es la participación de periodistas mexicanos y españoles que tomaron partido, ya sea a favor de Ballescá o en apoyo a De la Fuente Parres, lo que evidencia las diferencias ideológicas y la preferencia por adquirir un texto de historia o uno de religión, reflejo de la continuación de las discrepancias entre liberalismo y conservadurismo. Además, la discusión mostró que los escritores de México a través de los siglos eran colaboradores de La Prensa, lo que evidenciaba el papel que detentaban los peninsulares como editores que contrataban a letrados mexicanos de renombre.

Además de los periodistas mexicanos, José Barbier, director de La Voz de España, participó en la controversia a favor de Ballescá al que señaló como un editor que poseía antigüedad en el negocio editorial mexicano, dato erróneo, pues, como apunté antes, Santiago arribó a la República mexicana en 1870, cuando De la Fuente tenía siete años de residencia en el país, además, Barbier avaló la calidad de México a través de los siglos.

13 En la Biblioteca Nacional de México se encuentra la siguiente edición: La Sagrada Biblia; tr. de la Vulgata latina al español, aclarado el sentido de algunos lugares con la luz que dan los textos originales hebreo y griego, e ilus. con varias notas sacadas de los Santos Padres y expositores sagrados por Félix Torres Amat. Nueva ed. ilus. por Gustavo Doré. Barcelona, Montaner y Simón, 1883-1884. 4 vol. 
La postura de Barbier a favor de Ballescá y en contra de De la Fuente se explica a partir de las desavenencias que el editor de La Voz de España tenía con los miembros del Casino Español al que pertenecía el editor de La Prensa.

La disputa comercial también deja ver que el centro de producción editorial era Barcelona, ya que De la Fuente Parres evidenció que Ballescá sólo enviaría a Cataluña los textos de Riva Palacio, Vigil, Chavero y Olavarría para que la empresa Espasa los imprimiera. Esta práctica de intermediación editorial también la realizó De la Fuente, pues La Biblia sagrada que vendería en México saldría de la casa Montaner y Simón, con sede en Barcelona. Un aspecto más que destaca la disputa mercantil es el hecho de que Juan de la Fuente Parres fue respaldado por los redactores de El Tiempo, que se ocuparon de analizar las imágenes que acompañaban a México a través de los siglos. En esa revisión encontraron falta de concordancia entre el discurso histórico y las ilustraciones, lo que apoyaba la crítica que hizo De la Fuente en torno a la falta de calidad editorial del texto de Ballescá.

Además, el editor asturiano trató de generar discordia entre los colaboradores de México a través de los siglos. Apuntó que era injusto que Vicente Riva Palacio novelista, crítico literario y periodista - figurara como el coordinador de escritores como José María Vigil, Alfredo Chavero, Juan de Dios Arias y Julio Zárate. Ante esto, Chavero aprovechó las columnas de La Prensa para defender a Riva Palacio quien, según expresó, daba plena libertad a los colaboradores de la obra para redactar las partes que les fueron asignadas. De la Fuente fructificó los argumentos de Chavero para afirmar que Riva Palacio incumplía con el papel de director de México a través de los siglos, pues dejaba de lado coordinar la unidad de la obra, lo que también señala Pi-Suñer en su balance historiográfico. De la Fuente y Pi-Suñer coinciden en que Zamacois ejercía un método crítico del que carecía Riva Palacio y que los escritores de México a través de los siglos sabían que antes Zamacois había redactado una obra historiográfica de gran mérito que ellos tomaron como modelo. ${ }^{14}$

A partir de los años de 1883 a 1884, De la Fuente forjó alianza con Victoriano Agüeros, editor de El Tiempo, y con escritores de ideología conservadora, que al paso de los años le servirían para especializarse en la edición de obras religiosas. En este sentido, es viable mencionar la relación con la familia Arroyo de Anda, de origen jalisciense, que le servirá para establecer una librería en Guadalajara, la que referí antes. Es interesante destacar que está polémica editorial, permite abrevar más allá del libro y de los lectores, devela cómo las heridas entre liberales y conservadores aún no estaban cicatrizadas.

\footnotetext{
${ }^{14}$ Vale la pena señalar que Edith Leal indica que Ballescá estaba inconforme con el trabajo de José María Vigil porque escribía prolíficas explicaciones que restaban amenidad a México a través de los siglos, amén de que cobró dos veces por su trabajo (Leal, 2008: 162).
} 


\section{Epílogo}

Juan de la Fuente Parres falleció el otoño de 1922 en el océano Atlántico al realizar el trayecto en el vapor-correo alemán Holsatia. Al igual que los datos sobre su nacimiento, su deceso se permite dibujar a través de los periódicos, a los que en otro momento se sumaran otros documentos, para conocer el destino final del envejecido editor.

Los hijos de su primera y segunda esposa fijaron versiones distintas sobre los motivos que originaron ese viaje, con el fin de impugnar un testamento de valiosos bienes, lo que se anuda a que dos periódicos españoles informaron aspectos distintos sobre ese acontecimiento: El Cantábrico señaló que murió en el camino de Veracruz a La Habana, mientras que La Prensa (Santa Cruz de Tenerife) dijo que fue de la travesía de Cuba a Tenerife, el día 9 de septiembre "a consecuencia de una enfermedad de la vejiga" (La Prensa, 26 de septiembre de 1922: 1). Además, asentó que el señor De la Fuente tenía 75 años de edad, mientras que El Cantábrico señaló que eran 80 (El Cantábrico, 30 de septiembre de 1922: 2). Lo cierto es que su cadáver embalsamado estuvo unos días en el cementerio de Ciriego en Santander, luego se le llevó a Llanes, el pueblo en que nació.

Las páginas de los periódicos permiten documentar un acercamiento a la vida de este editor asturiano que, además de las novelas de Manuel Payno y la Historia de Méjico de Niceto de Zamacois, se ocupó de editar La Prensa, periódico que le posicionó entre los intelectuales mexicanos, a algunos de ellos los contrató como redactores, mientras que también tejió lazos y alianzas editoriales. A través de la hemerografía es posible identificar la trayectoria empresarial de Juan de la Fuente, así como fijar los giros comerciales que realizaron los migrantes asturianos en México, los lazos de parentesco, amistad y paisanaje que les unían en este país, que los llevaron a lograr una posición económica y cultural privilegiada.

Las publicaciones periódicas también son documentos que muestran la importancia de los asturianos como mediadores entre el comercio del libro catalán y mexicano. Aunado al hecho de que el mercado editorial en México registró la competencia de españoles que trataban de colocar sus productos entre los lectores de este país, así como ser favorecidos por sus compatriotas, lo que les llevó a desarrollar distintos proyectos editoriales acordes al interés de sus clientes que se distinguían por comprar obras de carácter religioso o textos con los que se identificaban los lectores de ideología liberal. Entre los escritores liberales mexicanos, De la Fuente fue un editor que mereció reconocimiento y gratitud por abrir espacios de trabajo que les permitieron ganarse la vida en la redacción de periódicos, lo que favoreció la producción intelectual de las postrimerías decimonónicas.

La información sobre Juan de la Fuente Parres obtenida en las publicaciones periódicas establece un amplio universo que abre la posibilidad de abordar distintos aspectos de la biografía de este editor asturiano, entre ellos, su desempeño como rico hacendado, 
aspecto que es poco conocido y que contribuirá a establecer el perfil y los diversos giros mercantiles de los migrantes asturianos residentes en México durante los siglos XIX y $\mathrm{XX}$.

\section{Bibliografía y fuentes hemerográficas}

AGÜEROS, V. (1884): “Gratitud”, en El Tiempo, no. 281, 6 de julio de 1884, pp. 4.

AYUNTAMIENTO DE LLANES. (1914): "Sección Municipal. Alcaldía de Llanes", en Boletín Oficial de la Provincia de Oviedo, no. 64, 20 de marzo de 1914, pp. 6.

“Bibliografía", en El Correo español, no. 1692, 17 de enero de 1896, pp. 1.

"Biblioteca Universal e llustración Artística”, en El Diario del Hogar, no. 212, 13 de junio de 1882 , pp. 2.

"Buques de Cuba", en La Prensa, Santa Cruz de Tenerife, no. 4006, 26 de septiembre de 1922, pp. 1.

CHAVARÍN, J., BRIONES, J., MACGREGOR, S. (1924): La verdad en el asunto De la Fuente Parres, México, Cultura.

“Circular", en El Tiempo, no. 1976, 8 de abril de 1890, pp. 3.

"El mayor teléfono de la República", en El Correo Español, no. 1949, 21 de noviembre de 1896, pp. 1.

“El señor D. Juan de la Fuente Parres", en La Prensa, no. 70, 6 de diciembre de 1884, pp. 1.

FUENTE PARRES, de la, J. (1894): Catálogo general de las obras que por suscripción y algunas completas ya, se hallan de venta en esta Casa Editorial, México, Despacho General.

- (1893) “Librería Religiosa”, en El Continental, no. 30, 22 de enero de 1893, pp. 3.

“Función dramática”, en El Siglo Diez y nueve, no. 18960, 27 de octubre de 1884, pp. 2.

GUTIÉRREZ, J., GUDIÑO, M. R., ROMERO, J. I., CONTRERAS, S. L. (2001): La memoria agraria mexicana en imágenes: cuatro ensayos, México, Registro Agrario Nacional, Archivo General Agrario, CIESAS.

"Juan de la Fuente Parres", en Boletín comercial, no. 51, 1 de septiembre de 1898, pp. 3. 
La Sagrada Biblia, tradición de la Vulgata latina al español, aclarado el sentido de algunos lugares con la luz que dan los textos originales hebreo y griego, e ilustrada con varias notas sacadas de los Santos Padres y expositores sagrados por Félix Torres Amat. Nueva ed. ilustrada por Gustavo Doré. Barcelona, Montaner y Simón, 1883-1884. 4 vol.

LEAL MIRANDA, E. (2008): "Santiago Ballescá. El editor en sus cartas", en Mora, P., Miquel, A., (editores) Españoles en el periodismo mexicano siglos XIX y XX, México, Universidad Nacional Autónoma de México, Instituto de Investigaciones Bibliográficas, Universidad Autónoma del Estado de Morelos, pp. 159-170.

LEÓN-PORTILLA, M. (1986): Diccionario Porrúa de historia, biografía y geografía de México, México, Editorial Porrúa: 2298.

“Libros en blanco", en El Monitor Republicano, no. 58, 9 de marzo de 1881, pp. 3.

“Marítimas. El Holsatia”, en El Cantábrico, no. 10441, 30 de septiembre de 1922: pp. 2.

MATEOS CARDEÑA, A. (1903): Apuntes de informe producido ante la Primera Sala del Tribunal Superior del Estado de México defendiendo los derechos del Sr. Don Juan de Fuente Parres en el recurso de apelación interpuesto contra la sentencia pronunciada por el juez de Primera instancia del Mineral de 'El Oro' en el juicio ejecutivo seguido contra los hermanos Salgado poseedores de la Hacienda de Jaltepec, México, Talleres Tipográficos de la Casa Editorial ‘J. de Elizalde'.

NORIEGA GAYOL, M. E. C. (2002): “Iñigo Noriega Laso. Un indiano durante el porfiriato y la revolución mexicana”, México, Tesis de licenciatura en historia, Universidad Nacional Autónoma de México, Facultad de Estudios Superiores Acatlán.

“Nueva construcción”, en El Tiempo, no. 2050, 6 de julio de 1890, pp. 3.

PASCUAL, E. (2010): “Un editor para la historia. Araluce y los libros”, Diario de León.es, 12 de diciembre de 2010. Disponible en internet (22-1-2019). https://www.diariodeleon.es/noticias/filandon/araluce-libros 570953.html

PI-SUÑER LLORENS, A. (2017): “Niceto de Zamacois, defensor y divulgador de la historia de México", en Suárez Argüello, A. R., Sánchez Andrés, A. (coordinadores), A la sombra de la diplomacia. Actores informales en las relaciones internacionales de México, siglos XIX y XX, México, Universidad Michoacana de San Nicolás de Hidalgo Instituto de Investigaciones Históricas, Instituto de Investigaciones Dr. José María Luis Mora, pp. 347-369.

- (2010): “Una mirada retrospectiva: la pugna historiográfica por la construcción de la identidad nacional, 1848-1902", en MacGregor, J. (coordinadora), Miradas sobre la nación liberal: 1848-1948. Proyectos, debates y desafíos. Libro 1. Discursos 
históricos, identidad e imaginarios nacionales, México, Universidad Nacional Autónoma de México, pp. 33-67.

PORTILLA, de la A. (1870): “Entierro", en La Iberia, no. 1128, 4 de diciembre de 1870, pp. 3.

“Postulaciones”, en La Patria de México, no. 2289, 9 de diciembre de 1884, pp. 2.

SCHMITT, M. (2001): "El folletinista y sus públicos. Notas acerca de la reedición de El fistol del diablo", en Olea Franco, R. (editor), Literatura Mexicana del otro fin de siglo", México, El Colegio de México, pp. 311-326.

“S. M. el rey don Alfonso XIII", en El Correo Español, no. 1858, 5 de agosto de 1896, pp. 3.

SOL, M. (2009): "La tradición impresa de Los bandidos de Río Frío", en Clark de Lara B., Company Company, C., Godinas, L., Higashi, A. (editores), Crítica textual. Un enfoque multidisciplinario para la edición de textos, México, El Colegio de México, Universidad Nacional Autónoma de México, Universidad Autónoma Metropolitana Unidad Iztapalapa, pp. 93-104.

TERCERO, J. N. (1890): "Nueva sociedad", en La Voz de México, no. 151, 5 de julio de 1890, pp. 2.

“Un español ingenuo y honrado" en El Tiempo, no. 7336, 31 marzo de 1905, pp. 2.

VIEYRA SÁNCHEZ, L. (2014): “Adolfo Llanos y Alcaraz. El ejercicio periodístico como expresión y poder de un sector hispano en México. La Colonia Española (18731879)". Tesis de doctorado en historia, México, Universidad Nacional Autónoma de México, Facultad de Filosofía y Letras.

- (2015): Los San lunes de Fidel y el cuchicheo semanario. Guillermo Prieto en La Colonia Española (enero-mayo de 1879), México, Universidad Nacional Autónoma de México, Coordinación de Humanidades, Programa Editorial. 